\title{
Fluxo migratório da população rural jovem da região de Presidente Prudente- SP
}

Migratory flow of the young rural population of the region of Prudente Presidente- SP

Flujo migratorio de la población rural joven de la región de Presidente Prudente - SP

\author{
Aline Alves de Freitas \\ Graduanda em Tecnologia em Agronegócio, Fatec de Presidente Prudente, Brasil. \\ adefreitasalves@gmail.com \\ Daniel dos Santos Viais Neto \\ Professor Doutor, Fatec de Presidente Prudente, Brasil. \\ dv.neto@fatec.sp.gov.br
}

\section{Edilene Mayumi Murashita Takenaka}

Professora Doutora, Fatec de Presidente Prudente, Brasil. edilene.takenaka@fatec.sp.gov.br 


\section{RESUMO}

A Teoria Malthusiana, datada do século XVIII, trouxe a preocupação de que a população da terra cresceria exponencialmente enquanto a produção de alimentos não acompanharia tal crescimento. Essa teoria foi desmentida no século XX com a Revolução Verde. Entretanto, outra preocupação deve ser levada em consideração, o êxodo rural, que vem reduzindo o número de produtores rurais, juntamente com a aparente falta de ânimo dos seus sucessores em continuar esse legado. Existem políticas públicas que buscam fortalecer esta permanência do homem no campo, porém, ainda é insuficiente para a sustentação dessa cadeia. Mediante tais afirmações, o presente trabalho teve por objetivo analisar o comportamento de pessoas com idades entre 18 e 40 anos que vivem e/ou trabalham na zona rural por meio de questionamentos que demonstram o interesse dos mesmos sobre a permanência no campo. Para tanto, foi realizada uma revisão bibliográfica seguida de uma pesquisa de campo auxiliada de um questionário. Os questionamentos buscaram saber dos entrevistados qual o sexo, a idade, o grau de escolaridade, onde moram, onde trabalham, os motivos pelos quais os mesmos permanecem ou migraram do campo e seus anseios em relação ao futuro. É possível concluir que os jovens entrevistados em sua grande maioria têm intensões de viver e/ou trabalhar no campo, mas há a necessidade de políticas públicas mais eficientes e de melhorias na infraestrutura para motiva-los a permanecerem no campo.

PALAVRAS-CHAVE: Êxodo. Zona Rural. Alimentos.

\section{ABSTRACT}

The Malthusian Theory, dating from the eighteenth century, brought concern that the earth's population would grow exponentially while food production would not keep pace with such growth. This theory was denied in the twentieth century with the Green Revolution. However, another concern must be taken into account, the rural exodus, which has reduced the number of rural producers, along with the apparent lack of motivation of their successors to continue this legacy. There are public policies that seek to strengthen this permanence of man in the field, but it is still insufficient to sustain this chain. The aim of this study was to analyze the behavior of people aged between 18 and 40 living and / or working in rural areas through questions that show their interest in staying in the countryside. For this, a bibliographical review was carried out followed by a field research aided by a questionnaire. The questions asked the interviewees their gender, age, educational level, where they live, where they work, the reasons why they remain or have migrated from the rural areas their plans for the future. It is possible to conclude that young people interviewed for the most part have intentions to live and / or work in the countryside, but there is a need for more efficient public policies and infrastructure improvements to motivate them to stay in the field.

Keywords: Exodus. Countryside. Foods.

\section{RESUMEN}

La Teoría Malthusiana, datada del siglo XVIII, traía la preocupación de que la población de la tierra crecer exponencialmente mientras la producción de alimentos no acompañaría tal crecimiento. Esta teoría fue desmentida en el siglo XX con la Revolución Verde. Sin embargo, otra preocupación debe ser tenida en cuenta, el éxodo rural, que viene reduciendo el número de productores rurales, junto con la aparente falta de ánimo de sus sucesores en continuar ese legado. Hay políticas públicas que buscan fortalecer esta permanencia del hombre en el campo, pero todavía es insuficiente para la sustentación de esa cadena. Mediante tales afirmaciones, el presente trabajo tuvo por objetivo analizar el comportamiento de personas con edades entre 18 y 40 años que viven y / o trabajan en la zona rural por medio de cuestionamientos que demuestran el interés de los mismos sobre la permanencia en el campo. Para ello, se realizó una revisión bibliográfica seguida de una investigación de campo auxiliar de un cuestionario. Los cuestionamientos buscaron saber de los entrevistados cuál es el sexo, la edad, el grado de escolaridad, donde viven, donde trabajan, los motivos por los cuales los mismos permanecen o migrar del campo y sus anhelos en relación al futuro. Es posible concluir que los jóvenes entrevistados en su gran mayoría tienen intensidades de vivir y / o trabajar en el campo, pero hay la necesidad de políticas públicas más eficientes y de mejoras en la infraestructura para motivarlos a permanecer en el campo.

PALABRAS CLAVE: Éxodo. Zona rural. Alimentos. 


\section{INTRODUÇÃO}

A Teoria Malthusiana considerava que as populações cresceriam em progressão geométrica, enquanto os meios de subsistência apenas em progressão aritmética, ou seja, segundo Thomas Malthus, essas condições elevariam o número da população da terra sem que fosse elevado o número de alimentos (CARNEIRO, 2003).

Essa teoria foi desmentida no século XX pelo progresso técnico da produção agrícola, conhecida por Revolução Verde. "A produção mundial de alimentos é suficiente para o adequado suprimento alimentar de toda a população" (GERGOLETTI, 2008).

O Brasil, por exemplo, é um país que consegue produzir seu próprio alimento, importando apenas US\$ 8.276 milhões e contando com exportação de US\$ 59.994 milhões, ao qual a população rural de apenas 29 milhões de pessoas é responsável pela alimentação de 204 milhões de brasileiros (FAO, 2015). Entretanto, o número dessa população vem caindo gradativamente desde 1974; este efeito nomeado de êxodo rural é o que vem a preocupar o abastecimento de alimento no país, pois $70 \%$ deste é proveniente de agricultura familiar (PORTAL BRASIL, 2015).

Outro fator importante para o país, é o Produto Interno Bruto (PIB) do agronegócio, que tem apresentando efeitos cada vez mais positivos à balança comercial brasileira, e segundo o Centro de Estudos Avançados em Economia Aplicada (2016), este acumulou alta de janeiro a julho de 2016 de 2,71\% em relação ao mesmo período no ano de 2015, porém, tal índice relacionado ao agronegócio não poderá continuar com sua contribuição se não houver os "pequenos produtores".

Por outro lado, existem programas de políticas públicas que buscam beneficiar e incentivar a cadeia de produtores tais como o Programa de Aquisição de Alimentos (PAA), o Programa Nacional de Abastecimento Escolar (PNAE) e o Programa Nacional de Fortalecimentos da Agricultura Familiar (PRONAF). Estes programas são alavancas importantes para o setor agropecuário e a manutenção do homem no campo, porém segundo Oliveira et al. (2014), os jovens brasileiros oriundos do campo continuam a abandonar a agricultura e o meio rural para procurar alternativas nas cidades.

Alves (2006) afirma que os jovens não têm ânimo para permanecer na sucessão de seus pais, e se as gerações futuras não permanecerem no meio rural, teremos menor produção de alimentos. Portanto, para que a agricultura familiar continue exercendo o papel importante para o país é necessário que estudos sobre a juventude rural sejam realizados, pois são eles os responsáveis pelo o futuro do setor e as eventuais mudanças que venham acontecer (CARVALHO et al., 2009).

Frente ao exposto, o presente trabalho teve por objetivo analisar o comportamento de pessoas com idades entre 18 e 40 anos que vivem e/ou trabalham na zona rural por meio de questionamentos que demonstram o interesse dos mesmos em permanecerem no campo. 


\section{METODOLOGIA}

O processo de desenvolvimento e execução deste trabalho foi feito por meio de levantamento bibliográfico (teses, dissertações monografias, artigos científicos, internet e livros) no que diz respeito aos temas êxodo rural, sucessão familiar e programas de políticas públicas destinados ao produtor.

Além disso, foi realizada uma pesquisa descritiva sobre a intensão do jovem em relação à vida e trabalho no campo, com foco em pesquisa de opinião. A pesquisa descritiva é a que ocorre quando se registra, analisa e correlaciona fatos ou fenômenos, sem manipulá-los (CERVO; BERVIAN; SILVA, 2007). É um método racional que dispensa comprovação experimental, baseando-se na observação ou aceitação de proposições tidas como evidentes sendo um axioma ou um princípio (SCHLITTLER, 2015).

Para realizar esta pesquisa, foi empregado um questionário a pessoas com idades entre $18 \mathrm{e}$ 40 anos, que residem e/ou trabalham na zona rural ou que já estiveram nessas condições, abrangendo a região de Presidente Prudente.

Neste questionário procurou saber dos entrevistados qual o sexo, a idade e o grau de escolaridade, onde moram e onde trabalham.

Em relação à onde moram, os mesmos foram questionados se sempre moraram na zona rural ou por qual motivo migraram para tal. De forma equivalente, foram indagados em relação a zona urbana.

Quanto ao trabalho, se os entrevistados fossem trabalhadores rurais, foram indagados com questões que dizem respeito à relação deles com a propriedade, seus interesses e satisfações. De forma equivalente, em caso de trabalhadores urbanos, questionou-se o motivo de não estarem trabalhando na zona rural.

\section{RESULTADOS E DISCUSSÃO}

A pesquisa foi realizada no mês de maio do ano de 2017. No total foram entrevistados 52 jovens da região de Presidente Prudente. As entrevistas ocorreram em feiras de produtores, propriedades rurais, faculdade e em comércio específico cuja maioria dos clientes são produtores rurais.

Nos três primeiros questionamentos, que se referiram a sexo, idade e escolaridade, a maioria dos entrevistados são do sexo masculino, possuem entre 21 e 25 anos de idade e cursam o ensino superior. Os percentuais desses questionamentos estão ilustrados nas Figuras 1, 2 e 3. 


\section{da Alta Paulista}

Figura 1: Percentual de gênero dos entrevistados

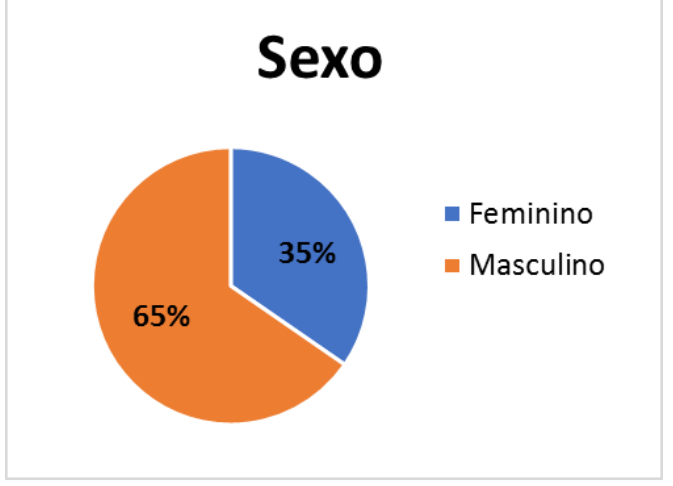

Fonte: Pesquisa de Campo.

Elaborada pelos autores.

Figura 2: Percentual das idades dos entrevistados

\section{Idade}

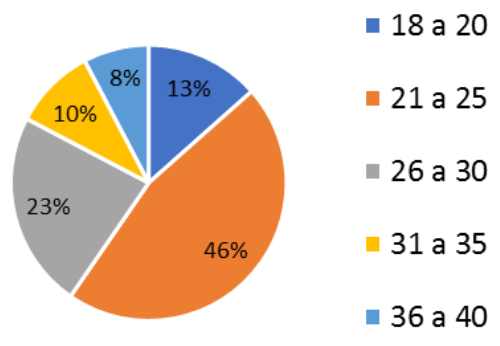

Fonte: Pesquisa de Campo.

Elaborada pelos autores.

Figura 3: Percentual do grau de escolaridade dos entrevistados

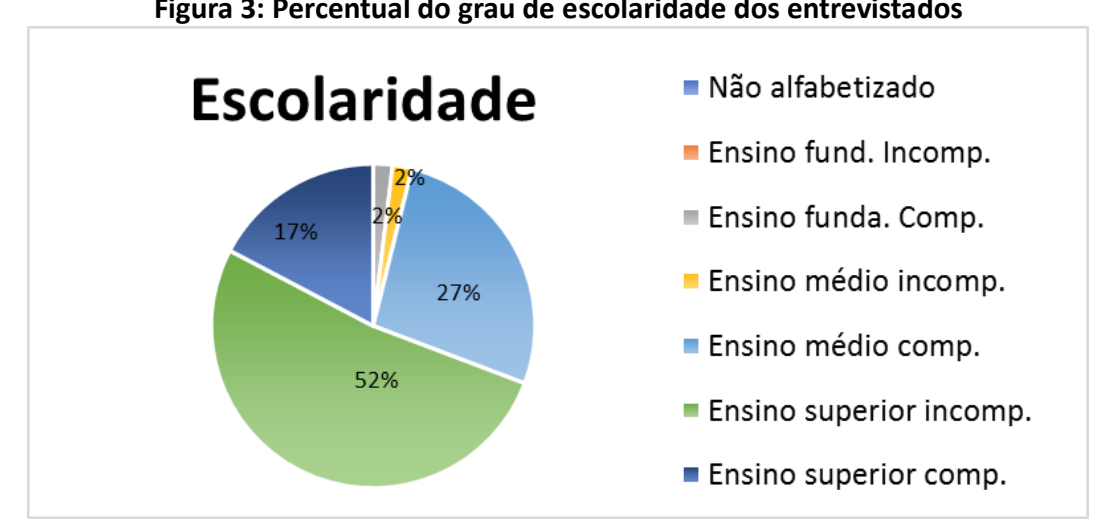

Fonte: Pesquisa de Campo.

Elaborada pelos autores.

Na sequência, procurou saber em que cidade os entrevistados residem (Figura 4) e em qual trabalham (Figura 5). Em relação à residência, 38\% declararam que moram em Presidente Prudente, seguido de 17\% em Alvares Machado, $11 \%$ em Rancharia e $36 \%$ em outros 
municípios. Já em relação ao local de trabalho, a maioria (42\%) declarou trabalhar em Presidente Prudente.

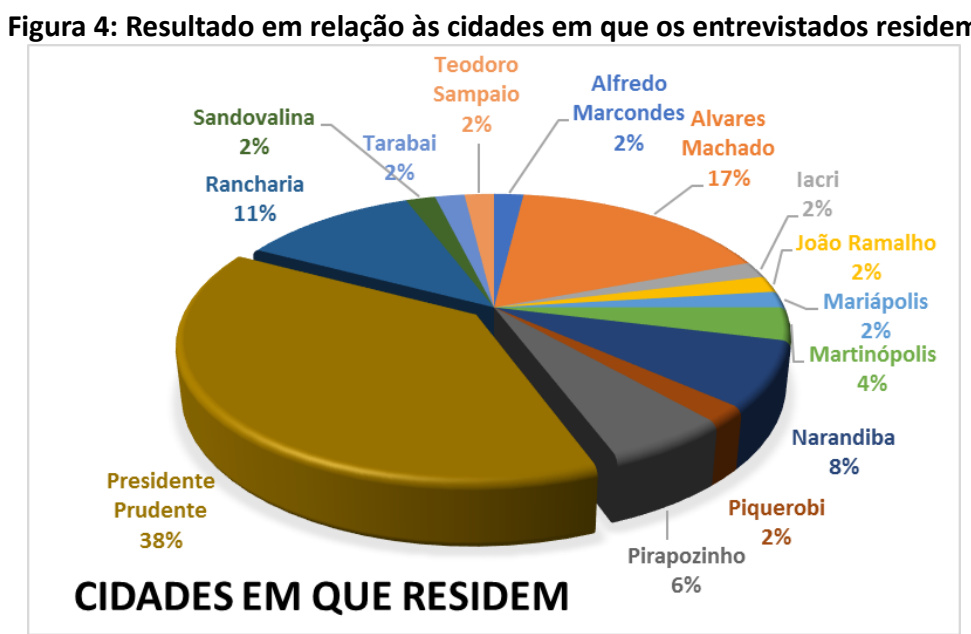

Fonte: Pesquisa de Campo.

Elaborada pelos autores.

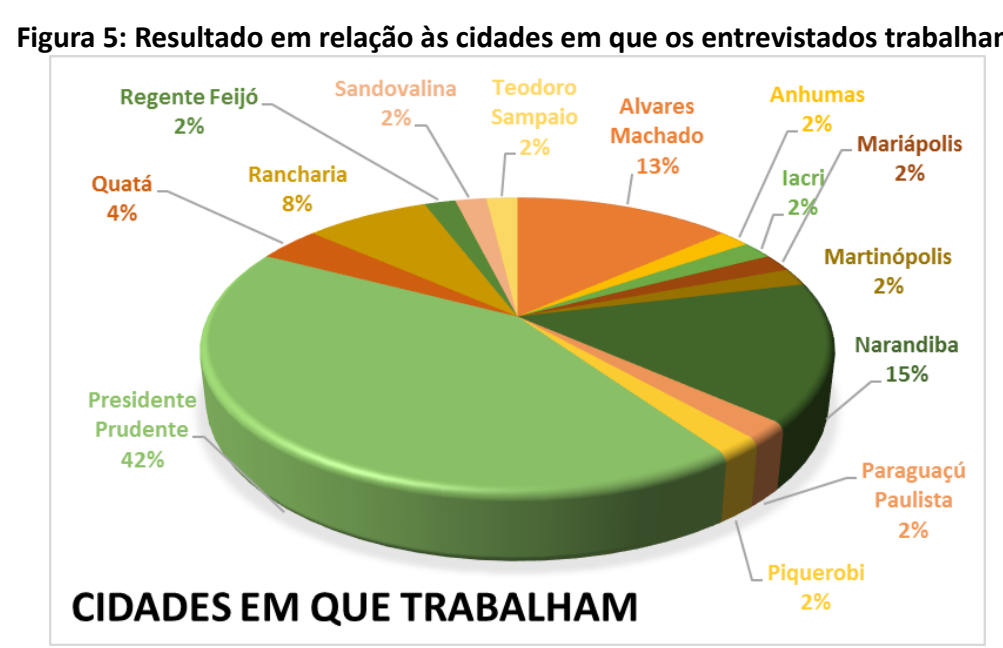

Fonte: Pesquisa de Campo.

Elaborada pelos autores.

Além do mais, a pesquisa apontou que o percentual $52 \%$ de entrevistados que vivem na zona rural (Figura 6a) é menor que o percentual dos que trabalham, 71\% (Figura 6b), ou seja, mesmo trabalhando na zona rural, existe uma tendência das pessoas em querer ou preferir morar na cidade.

Figura 6: Percentual de pessoas que (a) residem e (b) trabalham na zona rural 


\section{da Alta Paulista}

Volume 13, Número 05, 2017

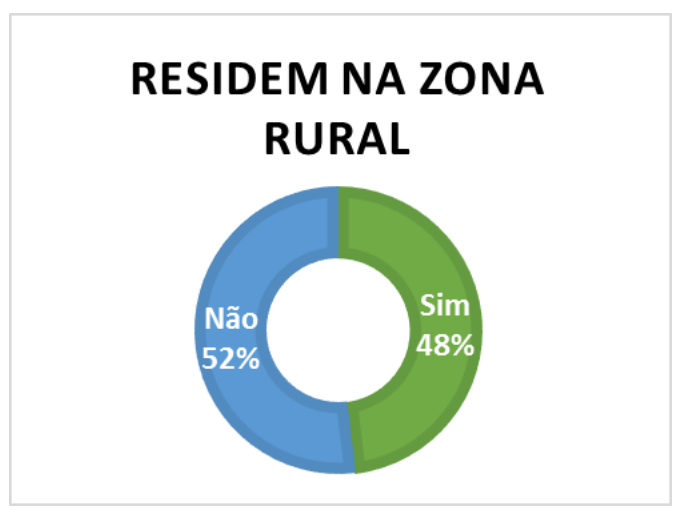

(a)

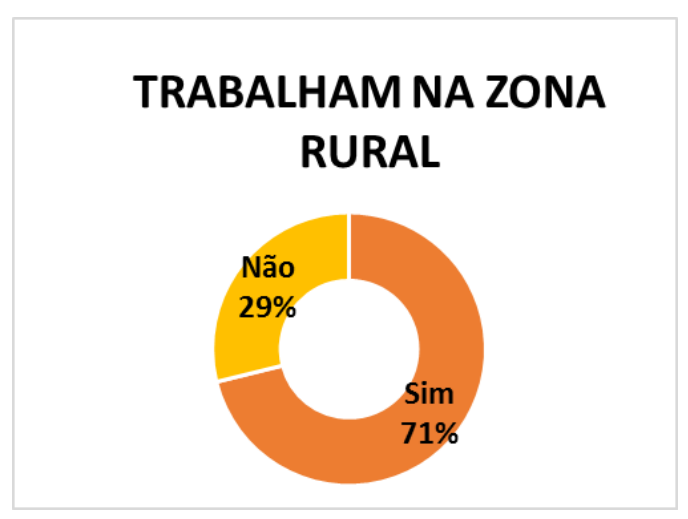

(b)

Fonte: Pesquisa de Campo.

Elaborada pelos autores.

Outra constatação interessante, foi a ocorrência de um percentual elevado de entrevistados que disseram sempre ter morado na zona rural $(72 \%)$, ao contrário dos que se declararam viver na zona urbana, onde constatou-se que $74 \%$ são provenientes da zona rural por motivos que serão discutidos no decorrer do texto (Figura 7).

Figura 7: Percentual de pessoas que sempre moraram (a) no campo e (b) na cidade

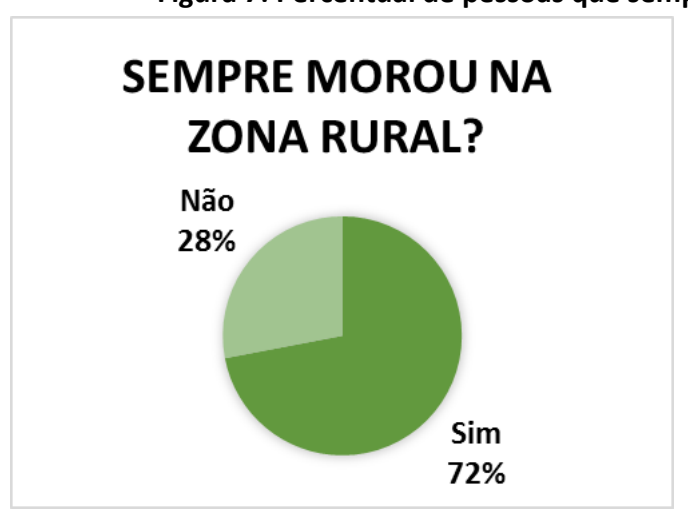

(a)

\section{SEMPRE MOROU NA ZONA URBANA?}

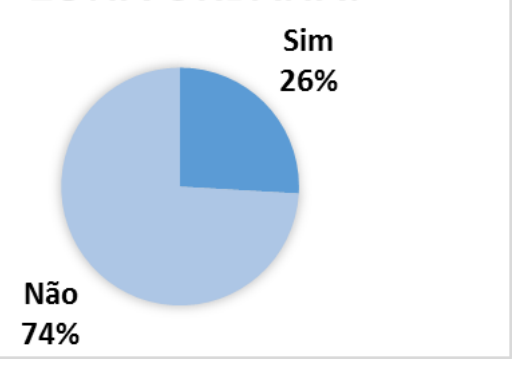

(b)

Fonte: Pesquisa de Campo.

Elaborada pelos autores.

Nos questionamentos, procurou-se investigar o que motivou o indivíduo a permanecer ou a se mudar tanto do campo quanto da cidade. A Figura 8, apresenta como um dos principais motivos, a influência da família nesta decisão, salvo quando perguntado o porquê se mudou para a cidade, onde a oportunidade de trabalho foi tão relevante quanto a família (Figura 8d). 


\section{da Alta Paulista}

Figura 8: Números a respeito da motivação das pessoas em (a) residirem no campo, (b) mudarem para o campo, (c) residirem na cidade e (d) mudarem para a cidade

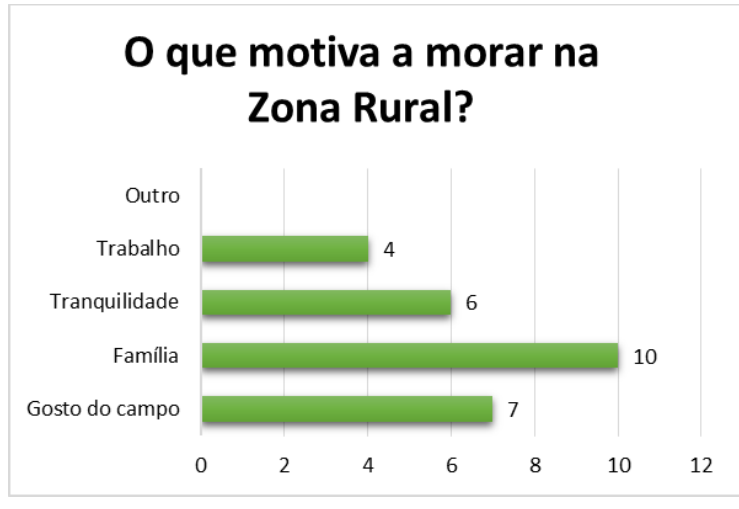

(a)

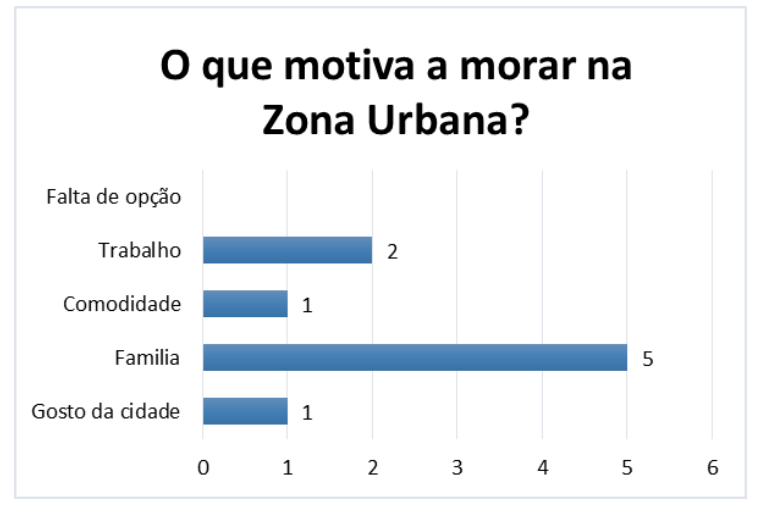

(c)

\section{O que motivou a mudar para a Zona Rural?}

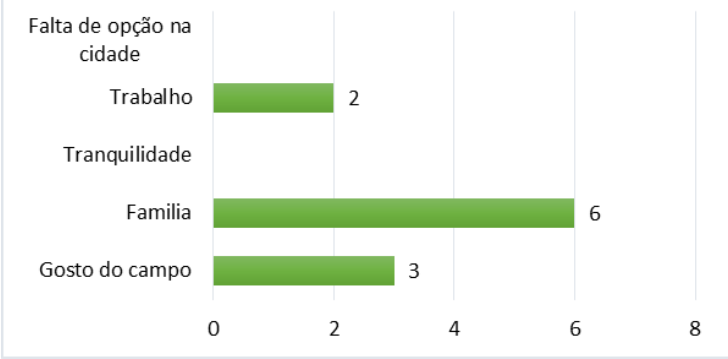

(b)

\section{O que motivou a mudar para a Zona Urbana?}

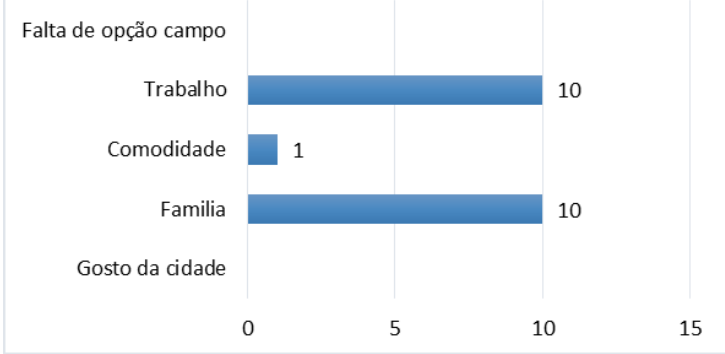

(d)

Fonte: Pesquisa de Campo.

Elaborada pelos autores.

As Figuras 9 e 10 representam os resultados dos questionamentos feitos aos entrevistados que se declararam trabalhar na zona rural.

A relação do indivíduo com a propriedade, apresentou $56,7 \%$ de proprietários, seguidos de $35,1 \%$ de funcionários e o restante de arrendatários (Figura 9a). Cabe ressaltar, que no percentual de proprietários, foi incluso também filhos de proprietários. Os entrevistados, quando perguntados sobre a principal motivação de trabalhar no campo, responderam que gostam do que fazem (Figura 9b). Na relação rendimentos / necessidades financeiras, de modo geral, se demonstraram satisfeitos (Figura 9c). Ainda, foi possível verificar que ocorreu uma diversidade de tamanhos das propriedades (Figura 9d), sendo que em $51 \%$ delas é praticada a agricultura familiar. Também vale ressaltar que, todos os entrevistados que se declararam ser funcionários, trabalham nas propriedades com mais de 50 ha. 
Figura 9. Números a respeito dos questionamentos direcionados a quem trabalha na Zona Rural

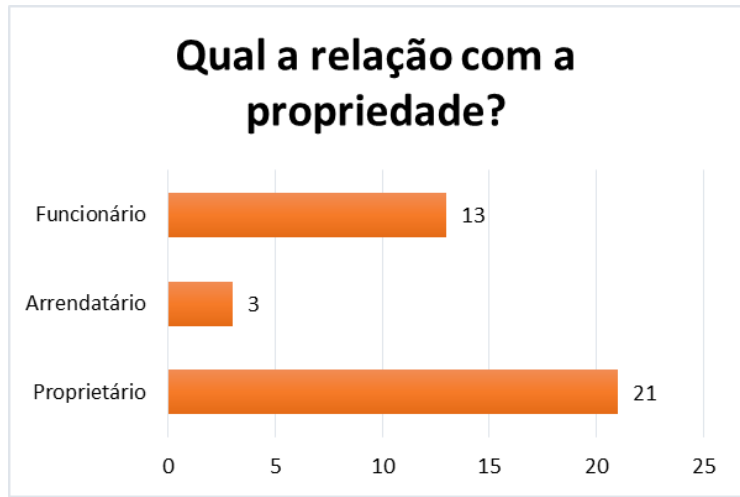

(a)

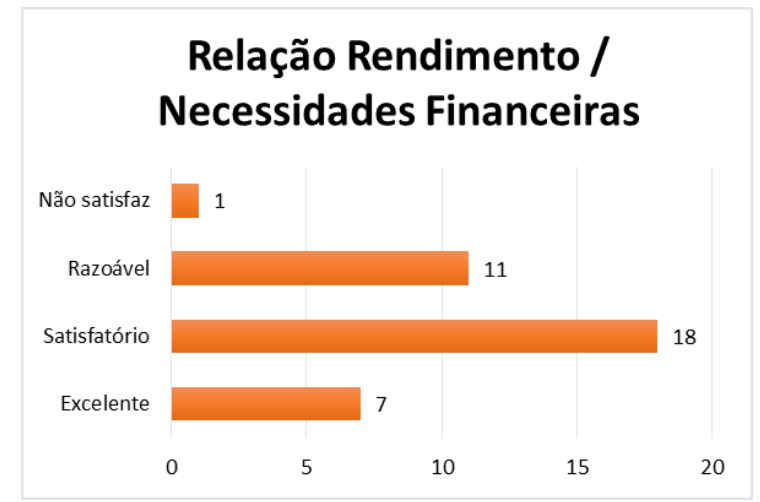

(c)

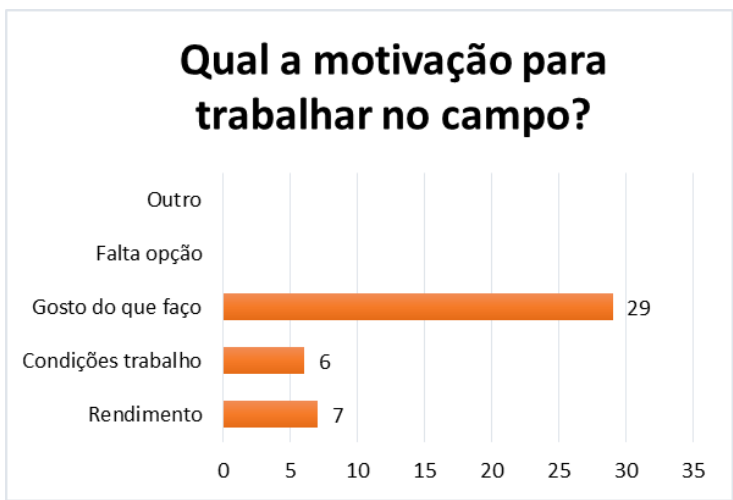

(b)

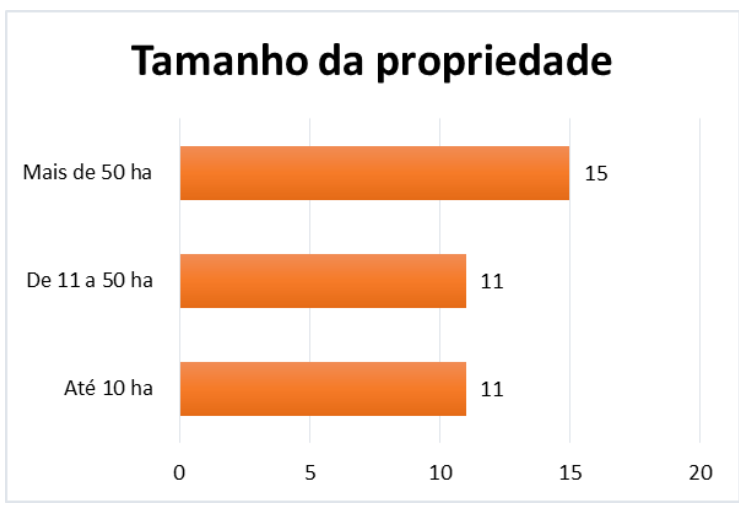

(d)

Fonte: Pesquisa de Campo.

Elaborada pelos autores.

Os questionamentos também demonstraram que grande parte dos entrevistados não participam de programas de incentivos (Figura 10a), muitos inclusive, declararam não participar devido a burocracia exacerbada, enquanto outros, já tentaram e não entendem o porquê não foram enquadrados, já que apresentam as características exigidas. Além disso, ao serem questionados quanto as suas expectativas de melhoria no campo, os mesmos apontaram melhores políticas públicas como o principal incentivador (Figura 10b), mostrando um descontentamento em relação aos programas já existentes, como foi discorrido acima, ou o desconhecimento dos mesmos. 


\section{da Alta Paulista}

Figura 10: Números a respeito dos questionamentos direcionados a quem trabalha na Zona Rural

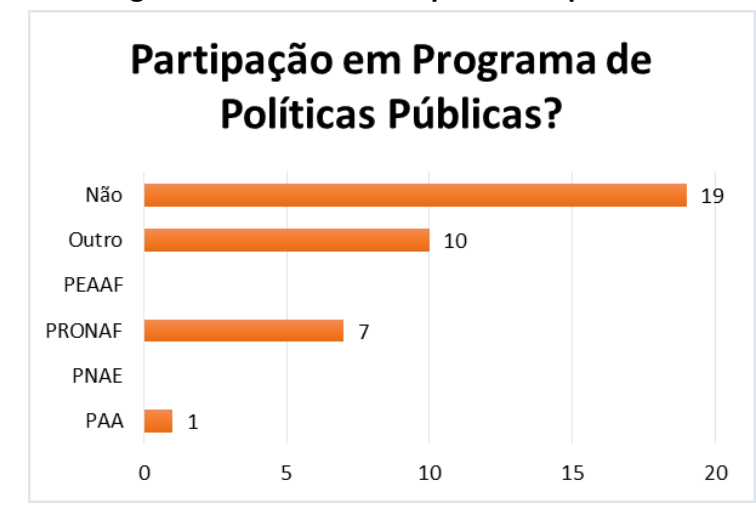

(a)

\section{O que levaria a ter melhores expectativas no campo?}

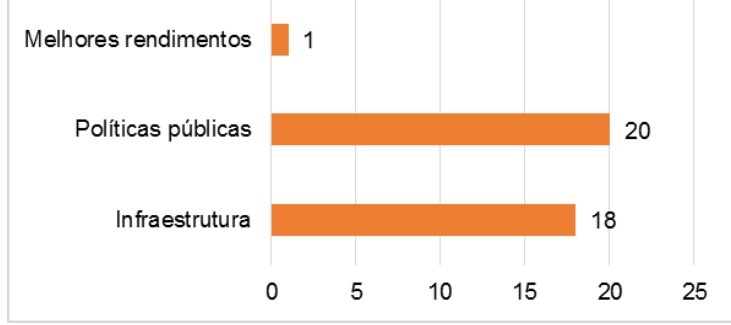

(b)

Fonte: Pesquisa de Campo.

Elaborada pelos autores.

Por fim, os entrevistados que se declararam morar na cidade, quando questionados a respeito do porquê não trabalham na zona rural, as respostas ficaram divididas entre não ter tido oportunidade ou preferência pela cidade (Figura 11).

Figura 11: Pessoas que não trabalham na zona rural

\section{Não trabalha na Zona Rural}

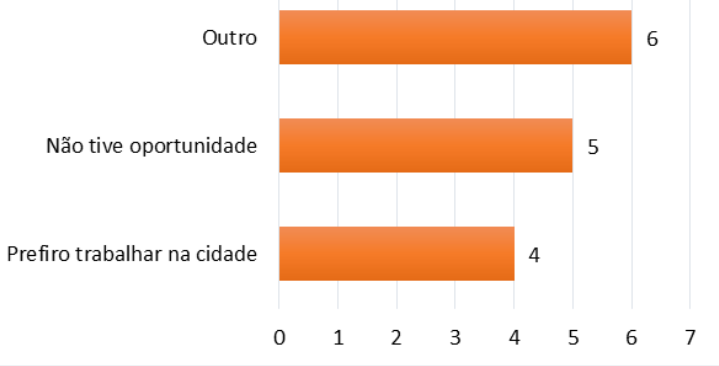

Fonte: Pesquisa de Campo.

Elaborada pelos autores.

Ainda na Figura 11, os entrevistados elencaram outros motivos tais como a desvalorização do produtor e a facilidade em poder conciliar trabalho com estudos como motivo de não trabalharem na zona rural.

\section{CONCLUSÃO}

Conclui-se que os jovens que têm ou tiveram alguma ligação com o campo, seja com relação à moradia ou com o trabalho, em sua grande maioria tem intensões de viver e/ou trabalhar no campo. Em muitos casos os jovens que se evadiram, o fizeram por questões de oportunidade de trabalho ou estudo na cidade ou para permanecer com a família, almejando retornar assim que possível. 
No geral, os que trabalham na zona rural, gostam do que fazem e todos declaram enxergar um futuro promissor nesta atividade, esperam que aconteçam melhorias na infraestrutura, tais como estradas, e acreditam que, políticas públicas mais eficientes seria uma grande motivação para sua permanência no campo.

\section{REFERÊNCIAS BIBLIOGRÁFICAS}

ALVES, E. Migração rural-urbana, agricultura familiar e novas tecnologias. Coletânea de artigos revistos. Empresa Brasileira de Pesquisa Agropecuária. Brasília, 2006.

CARNEIRO, H. Comida e sociedade: uma história da alimentação. 7. ed. Rio de Janeiro: Elsevier, 2003.

CARVALHO, D. M. et al. Perspectivas dos jovens rurais: campo versus cidade. Sociedade Brasileira de Economia, Administração e Sociologia Rural. Porto Alegre, 2009.

CENTRO DE ESTUDOS AVANÇADOS EM ECONOMIA APLICADA - CEPEA - USP. PIB do Agronegócio Brasil JULHO/2016. GDP Agribusiness - Brazil Outlook. Disponível em:

<http://www.cepea.esalq.usp.br/upload/kceditor/files/Relatorio\%20PIBAGRO\%20Brasil_JULHO.pdf>. Acesso em: jun. 2017.

CERVO, A. L.; BERVIAN, P. A.; SILVA, R. Metodologia científica. 6. ed. São Paulo: Pearson Prentice Hall, 2007.

FAOSTAT. Dados. Disponível em: <http://faostat.fao.org/beta/en/\#data>. Acesso em: nov. 2016.

GERGOLETTI, I. F. Produção de Alimentos: Uma Análise Comparativa de Cenários na Perspectiva da Sustentabilidade Ambiental. Tese (Doutorado em Engenharia de Produção) - Faculdade de Engenharia, Arquitetura e Urbanismo, da Universidade Metodista de Piracicaba (UNIMEP), Santa Bárbara d'Oeste - SP, 2008.

PORTAL BRASIL. Agricultura familiar produz $\mathbf{7 0} \%$ dos alimentos consumidos por brasileiros. Disponível em: <http://www.brasil.gov.br/economia-e-emprego/2015/07/agricultura-familiar-produz-70-dos-alimentosconsumidos-por-brasileiro>. Acesso em: nov. 2016.

OLIVEIRA, L. B.; RABELLO, D.; FELICIANO, C. A. Permanecer ou sair do campo? Um dilema da juventude camponesa. Revista Pegada, vol. 15, n. 1, 2014, p. 136-150.

SCHLITTLER, J. M. M. Como fazer monografias. 2. ed. Campinas: Servanda Editora, 2015, 304p. 